\title{
$\mathrm{Mn}$ 置換 Z 型へキサゴナルフェライトの結晶相および高周波磁気特性
}

\author{
和田 龍一, 柿崎 浩一, 平塚 信之 \\ 埼玉大学大学院理工学研究科, $\bar{\top}$ 338-8570 浦和市下大久保 255 .
}

\section{Crystal Phase and High Frequency Characteristics of Manganese Substituted Z-type Hexagonal Ferrites}

\author{
Ryuichi Wada, Koichi Kakizaki and Nobuyuki Hiratsuka \\ Graduate School of Science and Engineering, Saitama Univ., 255 Shimo-ohkubo, Urawa 338-8570.
}

Received February 28, 2000

\begin{abstract}
SYNOPSIS
A series of room-temperature ferromagnetic mixed oxides, $\mathrm{Ba}_{3} \mathrm{Co}_{2} \mathrm{Mn}_{\mathrm{X}} \mathrm{Fe}_{24 \mathrm{X}} \mathrm{O}_{41}$, with $\mathrm{z}$-type structure, has been synthesized by high temperature solid-state reaction. $\mathrm{Ba}_{3} \mathrm{Co}_{2} \mathrm{Mn}_{\mathrm{X}} \mathrm{Fe}_{24 \mathrm{x}} \mathrm{O}_{41}$ was made from $\mathrm{BaCO}_{3}, \mathrm{CoO}, \mathrm{Mn}_{2} \mathrm{O}_{3}$ and $\alpha-\mathrm{Fe}_{2} \mathrm{O}_{3}$. The structure was determined by $\mathrm{x}$-ray diffraction method; single phase with $\mathrm{z}$-type structure was obtained for $\mathrm{Ba}_{3} \mathrm{CO}_{2} \mathrm{Mn}_{\mathrm{x}} \mathrm{Fe}_{24-\mathrm{x}} \mathrm{O}_{41}(\mathrm{x}=0,1,2)$. Frequency dependence of initial permeability of all samples was investigated. The initial permeability of $\mathrm{Ba}_{3} \mathrm{Co}_{2} \mathrm{Mn}_{1} \mathrm{Fe}_{23} \mathrm{O}_{41}$ was 13 (at $0.1 \mathrm{MHz}$ ), which was highest of all samples. One of the reasons is due to the change of magnetocrystalline anisotropy which caused by $\mathrm{Mn}$ ions and $\mathrm{Fe}$ ions. The other is decrease of the magnetostriction caused by Jahn-Teller effects which induced by $\mathrm{Mn}^{3+}$ ions.
\end{abstract}

KEY WORDS

Ferroxplana, substitution, Z-type ferrite, Initial permeability, Jahn-Teller effects

\section{1 緒言}

近年,様々な電子機器のデジタル化および高性能化が進み， 各種テバイスに要求される周波数が $\mathrm{MHz}$ 帯から $\mathrm{GHz}$ 帯へ移 行している.これに伴い,これまで使用されてきた Ni-Znフェ ライトに代表される立方晶系フェライトのインダクター材料

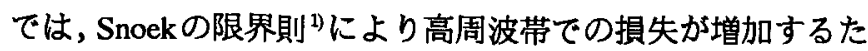
め対応できない.また，ノート型パソコンのCPU等の動作周 波数の高周波化に伴う EMI問題も重要な課題となったきてお り，これまで使用されてきた立方晶系のフェライトの許容周 波数を超えるノイズ対策用材料か心必要である.そこでこれら の要請に応え得る材料として, c軸方向と $\mathrm{c}$ 面方向の異方性磁 界の大きさが異なるためSnoek の限界を越える特性を持つ六 方晶系のフェライトが検討されてきた．これらの中でも $\mathrm{Co}_{2} \mathrm{Z}\left(\mathrm{Ba}_{2} \mathrm{Co}_{3} \mathrm{Fe}_{24} \mathrm{O}_{41}\right)^{2,3)}$ は，c面内に磁化容易軸があるため透磁 率が比較的高いことが知られている。しかし，単相が得にく いこと，初透磁率の温度係数が大きいこと，および高い焼成 温度を要する等の原因により，実用化された例は少ない。

ところで，上述の Z型フェライトに類似した構造である六
方晶系 $\mathrm{M}$ 型バリウムフェライト $\left(\mathrm{BaFe}_{12} \mathrm{O}_{19}\right)^{4,5}$ において $\mathrm{Fe}^{3+}$ $\mathrm{Mn}^{3+}$ で置換することにより $\mathrm{c}$ 軸方向の異方性磁界が増大する と報告されている6っ. そこで，著者等は Z型フェライトにお いても $\mathrm{Fe}^{3+}$ を他の金属イオンで置換することにより，M型 フェライトと同様の効果を $\mathrm{Z}$ 型フェライトにも期待し，初透 磁率の限界周波数を高くすることを検討した ${ }^{8)}$. Mnイオンは 様々な価数をとり得るため, 複雑な電子構造の $\mathrm{Z}$ 型フェライ トの電荷バランスがとりやすく，単相の生成が容易になる可 能性があると考えた.さらに，立方晶系の $\mathrm{Mn}$ フェライトにお いては $\mathrm{Mn}^{2+}$ イオンが4面体位置に $80 \%$ 入り，中間型スピネル 構造となることが知られており ${ }^{9}$ ，型フェライトにおいても $\mathrm{Fe}^{3+}$ イオン, $\mathrm{Mn}^{2+}$ イオン, $\mathrm{Mn}^{3+}$ イオンおよび $\mathrm{Mn}^{4+}$ イオンが配 位する状態によって磁化值および磁気異方性に影響を与える と考えられる。

したがって，本研究では，高周波材料として有望な $\mathrm{Co}_{2} \mathrm{Z} の$ $\mathrm{Fe}^{3+}$ イオンを $\mathrm{Mn}^{3+}$ イオンで置換することにより，初透磁率の 周波数特性の改善およびZ相の容易な生成を目指すとともに， それらの磁気特性について検討した。 


\section{2 実験方法}

試料は通常のフェライトバルク作製法を用いた. 出発原料 に $\mathrm{BaCO}_{3}, \mathrm{CoO}, \mathrm{Mn}_{2} \mathrm{O}_{3}$ および $\alpha-\mathrm{Fe}_{2} \mathrm{O}_{3}$ を用い， $\mathrm{Ba}_{3} \mathrm{CO}_{2} \mathrm{Mn}_{\mathrm{x}} \mathrm{Fe}_{24} \mathrm{O}_{41}$ (X=0〜2.0)の組成に秤量した.これらの粉体をボールミルで 10 時間混合し $1250^{\circ} \mathrm{C} て ゙ 2$ 時間, 大気中で仮焼成を行った後, 遊星ボールミルで 20 分粉砕した.こうして得られた仮焼成粉 をトロイダル状に成型した後, 再び $1250^{\circ} \mathrm{C} て ゙ 2$ 時間, 大気中 で本焼成した。焼結体の結晶構造は，X線回折法 (XRD) で同 定した. 焼結体の表面の微細構造は走査型電子顕微鏡 (SEM) により観察した。磁化值およびその温度依存性は振動試料型 磁力計(VSM)で測定した. 初透磁率の周波数特性はインピー ダンスアナライザ(HP4284A)で0.001〜1.8GHzまで測定した. また，試料の Fe および Mnのイオン状態は ESCAにより決定 した.

\section{3 実験結果および考察}

$3.1 \mathrm{Ba}_{3} \mathrm{Co}_{2} \mathrm{Mn}_{\mathrm{X}} \mathrm{Fe}_{24 \times} \mathrm{O}_{41}$ の結晶相

Fig. 1 は $1250^{\circ} \mathrm{C} て ゙$ 本焼成した置换量 $\mathrm{X}=0,1,2$ の試料の $\mathrm{X}$ 線 回折図を示す. $\mathrm{X}=0,1,2$ のいずれの試料においても $\mathrm{Z}$ 型フェ ライトの単相が得られた. 次に, Fig.2は X $=0,0.5,1,1.5,2$ の 試料の初透磁率の周波数依存性を示す. $\mathrm{X}=0$ および 0.5 では 初透磁率が 11 である. 置換量が X=1 は 13 となる.しかし,さらに置換量の多いX=1.5および2で は初透磁率は 9 となり，X=0に比較して減少する. Fig.3は， $100 \mathrm{MHz}$ における初透磁率および限界周波数のX依存性を示 す.ここで，限界周波数は $\mathrm{Q}=1$ のときの值と定義した. $\mathrm{X}=1$ のように初透磁率の高い組成ほど限界周波数が低く，逆に限 界周波数か高い組成は初透磁率が低くなる傾向がある.また，

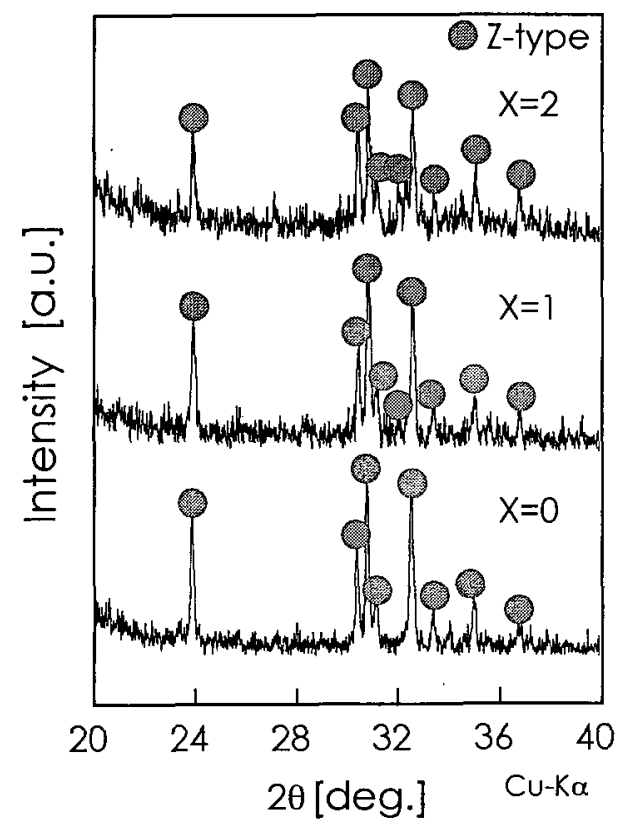

Fig.1 X-ray diffraction diagrams for $\mathrm{Ba}_{3} \mathrm{CO}_{2} \mathrm{Mn}_{\mathrm{X}} \mathrm{Fe}_{24-\mathrm{x}} \mathrm{O}_{41}$ sintered at $1250^{\circ} \mathrm{C}$.
$\mathrm{X}=1$ の組成のように初透磁率が上昇する要因を挙げると，粒 径の増大, 密度の向上, 磁化值の上昇, 結晶配向の寄与およ び磁気異方性の低下がある. 従ってこれらの要因について順 次検討した.

\section{2 $\mathrm{Ba}_{3} \mathrm{Co}_{2} \mathrm{Mn}_{1} \mathrm{Fe}_{23} \mathrm{O}_{41}$ の磁気特性および微細構造}

Fig.4は，室温における磁化值の Mn イオン置换量 X依存性 を示す．置換量が增加するに従い磁化值加減少する．また， $\mathrm{X}=1$ の磁化値は, $\mathrm{X}=0$ より小さい值であるため, $\mathrm{X}=1$ にお ける初透磁率の上昇は，磁化值は直接的には対応していない と思われる。

Fig.5は, $X=0$ および 1 の試料の表面 SEM 写真を示す. $X=0$ および 1 の結晶粒径はともに $2 \sim 10 \mu \mathrm{m}$ で同様な六角板状の粒

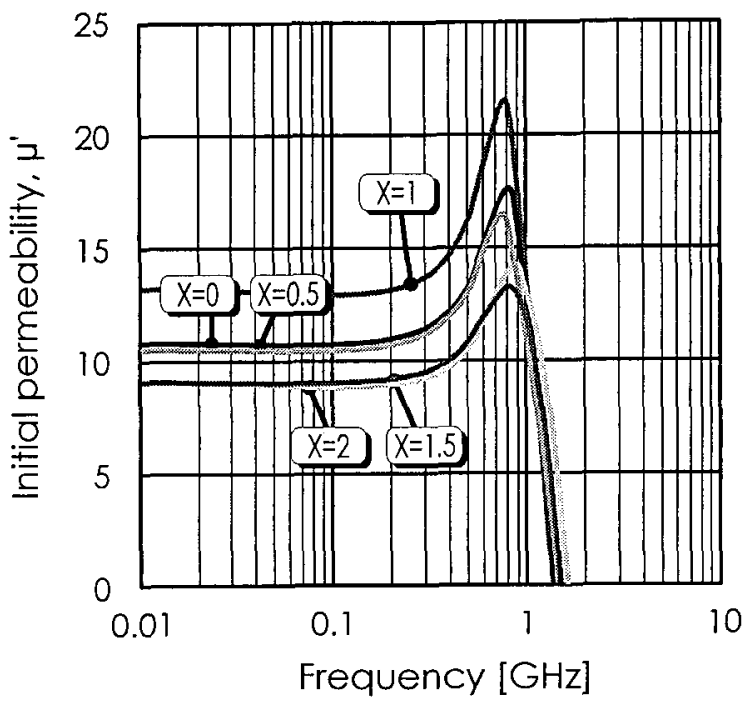

Fig.2 Frequency dependence of initial permeability for $\mathrm{Ba}_{3} \mathrm{Co}_{2} \mathrm{Mn}_{\mathrm{X}}$ $\mathrm{Fe}_{24-\mathrm{X}} \mathrm{O}_{41}(\mathrm{X}=0,0.5,1,1.5,2)$ sintered at $1250^{\circ} \mathrm{C}$ for $2 \mathrm{~h}$ in air.

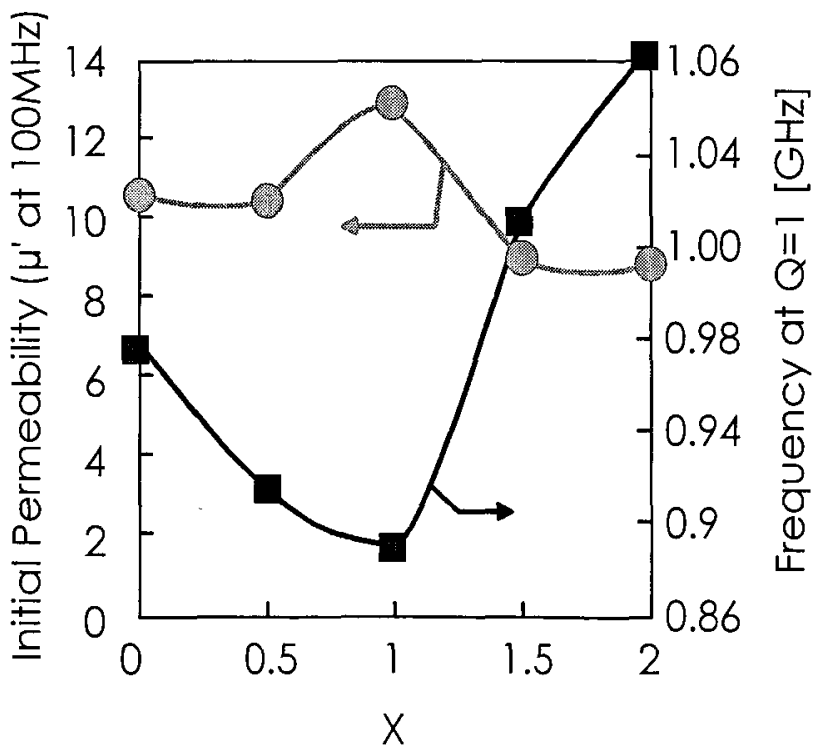

Fig.3 Composition dependence of initial permeability (at $100 \mathrm{MHz}$ ) and frequency limit $(Q=1)$. 
子形態である. $X=1$ の粒子表面に見られるステップ状の縞模 様は粒成長の途中段階であると推察される. また，アルキメ テス法により,これら試料の焼結密度を測定した. 各々の密 度は $\mathrm{X}=0$ が $4.55 \mathrm{~g} / \mathrm{cm}^{3}, \mathrm{X}=1$ が $4.44 \mathrm{~g} / \mathrm{cm}^{3}$ であり，逆に初透磁 率の高い $\mathrm{X}=1$ の密度の方が低い值となった. 従って, これら 試料の粒径および密度は初透磁率の差異に影響を及ほしてい

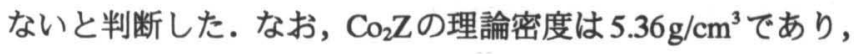
$\mathrm{X}=0$ の相対密度はその $84.9 \%$ で改善の余地がある.

作製した焼結体は，粉砕した仮焼成粉をトロイダル状の金 型に充填し, 一軸加圧した後, 焼成したものである. 従って, 六方晶フェライトに特有な板状粒子が成型の際, 加圧軸方向 に配向する可能性があるので粒子の配向性を検討した. Fig.6 は, $\mathrm{X}=1$ の試料について種々の状態を測定したX線回折図を 示す. 図中の (a), (b), (c) および (d) はそれぞれ混合粉をペレッ 卜状にして仮焼成した試料(a), (a)の仮焼成粉をボールミル粉 砕しトロイダル状に成型し本焼成した試料(b), (b)の上面を約 $0.5 \mathrm{~mm}$ 削った試料 (c), (b) の側面を約 $2 \mathrm{~mm}$ 削つた試料 (d) の X線回折図である. (a)に比べて (b)の結晶相においては $\{001\}$ 面からの回折ピークが増大する. しかし, 上面あるいは側面 を削った(c), (d)を(b) と比較すると $\{001\}$ 面からの回折ピーク は減少し，仮焼成の状態 (a) と同様のピーク強度比となる. 従って,試料の表面層のみが配向していることが確認される.

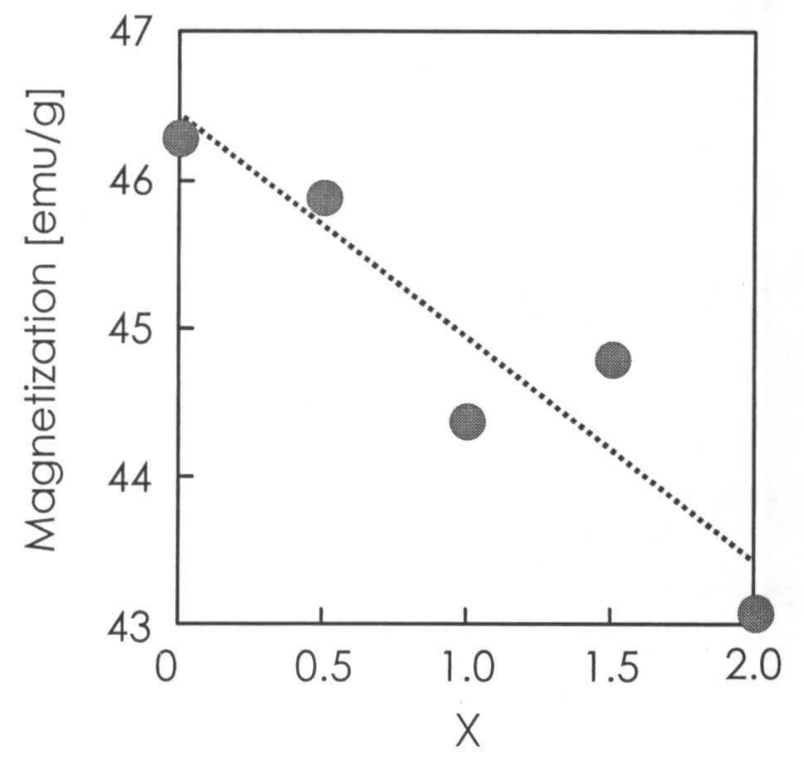

Fig.4 Saturation magnetization as a function of composition.
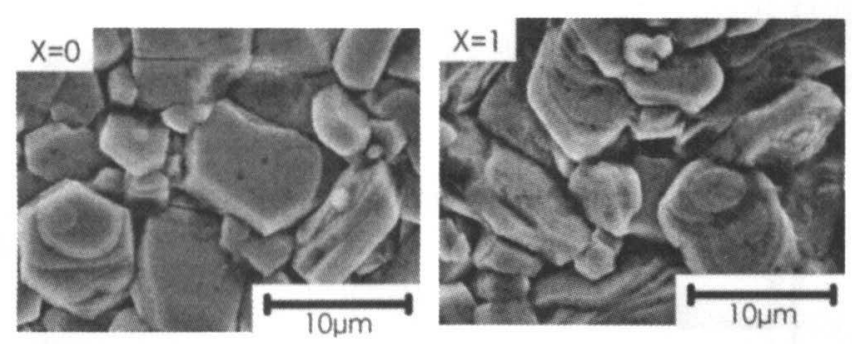

Fig.5 SEM photograph of Z-type ferrite $\mathrm{Ba}_{3} \mathrm{Co}_{2} \mathrm{Mn}_{\mathrm{X}} \mathrm{Fe}_{24-\mathrm{x}} \mathrm{O}_{41}(\mathrm{X}=$ $0,1)$.
本烤成前の成型体表面も X線回折により確認したところ, 金 型と仮焼粉の接触面でのみ, 仮焼粉が形状配向したことが確 認された. そこで, 表面層の配向が初透磁率に及ぼす影響を 検討するため, 試料の加圧軸方向の表面配向層を両面合わせ て約 $1 \mathrm{~mm}$ 削り, 削る以前の試料と磁気特性を比較した。

Fig.7は, 試料の表面配向層を削った試料および削る以前の 試料の初透磁率の周波数依存性を示す. 表面層を削った試料 の初透磁率は上昇する.これは, 表面層のみ結晶粒子が配向 し, 試料表面に応力が加わっていると考えられる. 表面の配 向層を削ったため, それが緩和され，その結果，初透磁率か 上昇したと推測される.

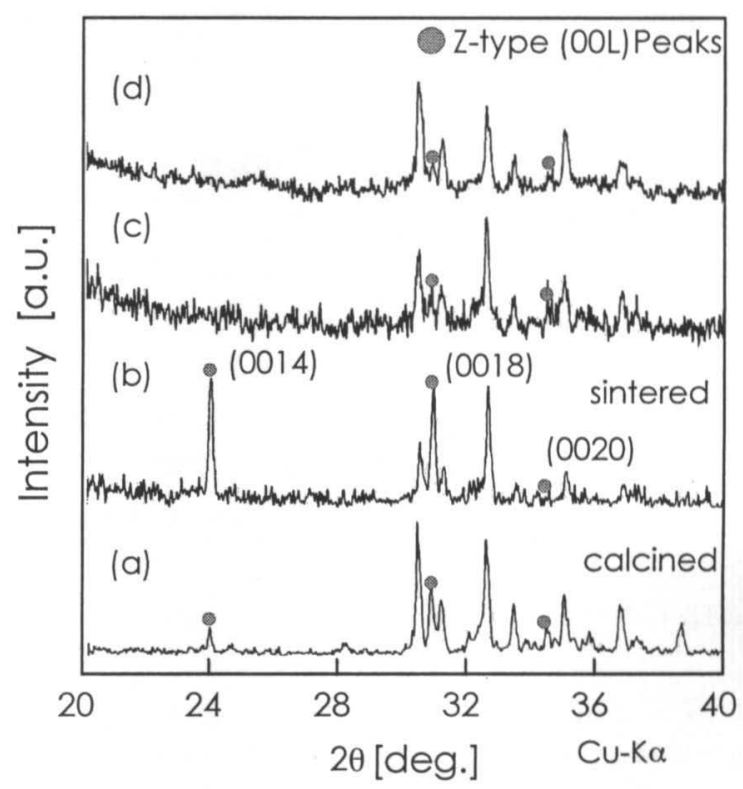

Fig.6 X-ray diffraction diagrams for (a) calcined, (b) sintered, (c) sample grinded upper plane, and (d) sample grinded the side of toroidal cores.

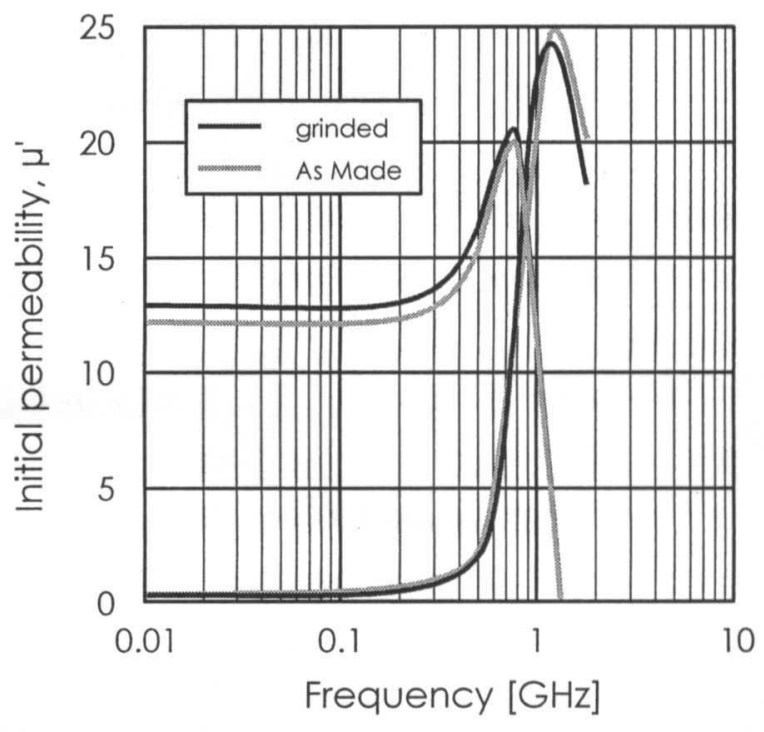

Fig.7 Frequency dependence of initial permeability for sample as made $(X=1)$ and sample grinded oriented phase. 
Fig.8 は，X=0,1,2の透磁率の変化率の温度依存性を示す. 透磁率の変化率は，室温 $25^{\circ} \mathrm{C}$ を基準として $\Delta \mu=\left(\mu_{25}-\mu_{T}\right) \mu_{25}$

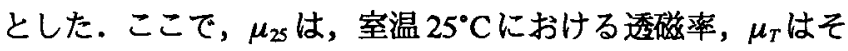
れぞれの温度における透磁率である.X=1において最も小さ い変化率となる.置换量が $\mathrm{X}=2$ の試料は, $\mathrm{X}=0$ よりも変化率 は大きい. また, 透磁率の変化率に見られる極小となる点は， 置換量の增加に伴って低温側へ移行した. 透磁率の変化率の 極小点は異方性が0であると考えられる.すなわち，Mnイオ ンで置換したことにより磁気異方性が変化することが示唆さ れる.また，磁気異方性の変化は $\mathrm{Mn}^{3+}$ の効果ばかりでなく $\mathrm{Fe}$ イオンおよびMnイオン状態の変化によっても磁気異方性が 変わる. 従って，これらの金属イオンの存在状態を ESCAに より検討した.

Fig.9(a) および(b)は，それぞれ X=0,1,2 の試料の Fe イオ

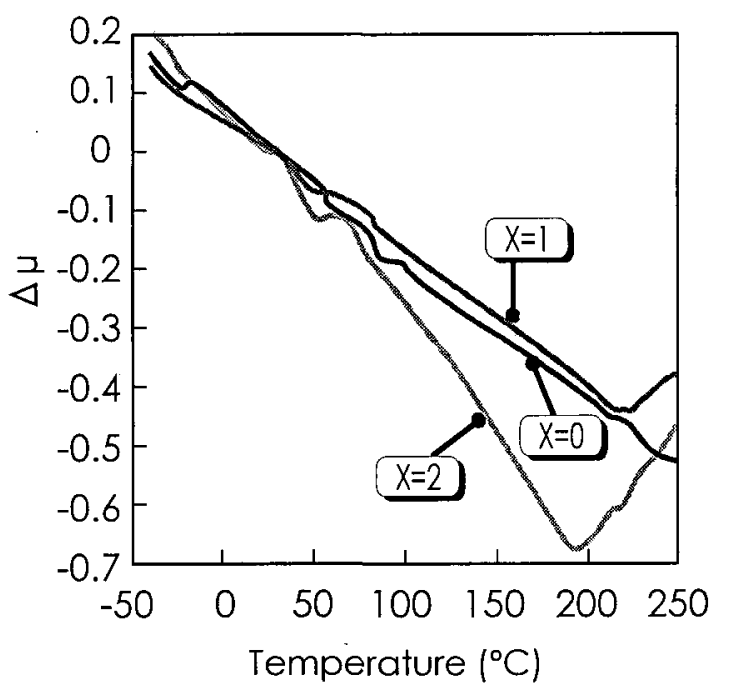

Fig.8 Change rate of initial permeability for various compositions as a function of temperature.

(a)

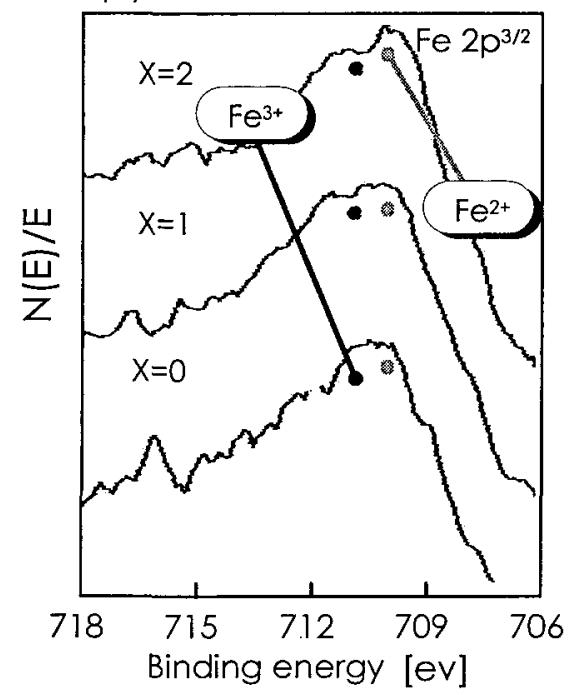

ンおよびMnイオンのESCAスペクトルを示す.なお，測定時 には表面を研磨した試料を用い，さらにアルゴンスパッタを した.Mnイオン置換量が増えるに従い Feイオンの状態は， $\mathrm{Fe}^{2+}$ が相対的に增加している。一方, Mnイオンの状態につい ては, $\mathrm{X}=1$ では $\mathrm{Mn}^{3+}$ の状態で主に存在していると考えられ

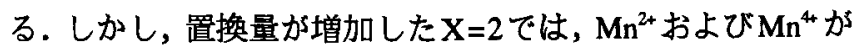
$\mathrm{X}=1$ の場合に比べ相対的に增加している.これらの Mnイオ ンおよびFeイオン状態も磁気異方性の変化に寄与していると 推察される. 以上の結果から，初透磁率が上昇したと考察し

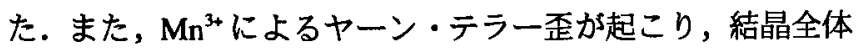
の歪を逆に緩和した結果, 初透磁率が上昇したということも 考えられる.一方, 初透磁率の温度特性においても $\mathrm{Mn}^{3+}$ の笴

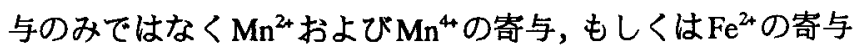
もあると判断した。

Fig.10は, キュリー温度の Mn 置換量 X依存性を示す.キュ リ一温度は, 置換量の増加とともに低温側へシフトしている. このX=1 および2のキュリー温度と Fig.7のX=1 および2の 極小点を生じる温度を各々比較すると温度差が $200^{\circ} \mathrm{C}$ 近くあ り, Fig7のX=1および2の極小点は, 異方性定数の正負が反 転した結果, 出現したものと推察されるれ.しかし，この極小 点は Mnイオンがスピネルブロックに配䁬することで生じる

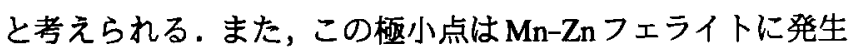
するセカンダリーピーク ${ }^{10)}$ に相当する可能性もあり，さらに 高温側の測定が必要である。

\section{4 ま と め}

限界周波数の向上，容易な $\mathrm{Z}$ 相の単相化および初透磁率の

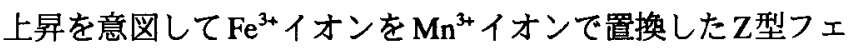
ライト $\left(\mathrm{Ba}_{3} \mathrm{Co}_{2} \mathrm{Mn}_{\mathrm{x}} \mathrm{Fe}_{24-\mathrm{x}} \mathrm{O}_{41}\right)$ を作製し，磁気特性および結晶構 造を調べたところ以下の結果が得られた。

（1）焼成条件を最適化することにより，X=0〜2.0のすべての

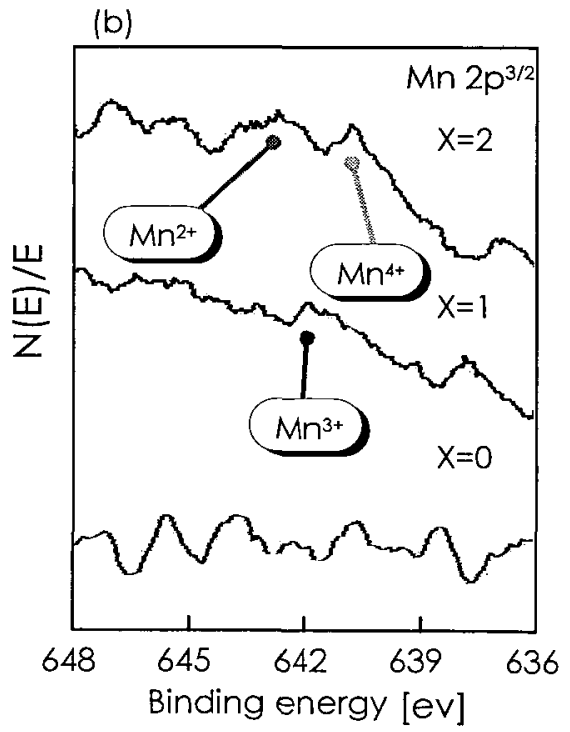

Fig.9 XPS spectra of $\mathrm{Fe}$ ions and $\mathrm{Mn}$ ions for $\mathrm{Ba}_{3} \mathrm{Co}_{2} \mathrm{Mn}_{\mathbf{X}} \mathrm{Fe}_{24-\mathrm{X}} \mathrm{O}_{41}(\mathrm{X}=0,1,2)$. 


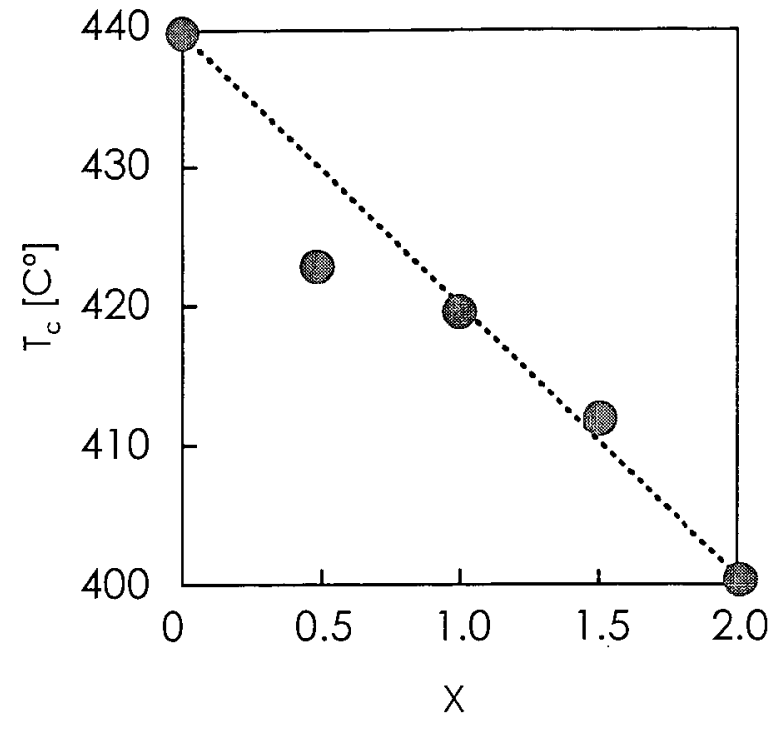

Fig.10 Curie temperature as a function of composition.

組成において Z 相単相が得られた。

(2) 置換值 $\mathrm{X}=1$ において, 初透磁率 13 , 限界周波数 $0.88 \mathrm{GHz}$ となり，X=0の初透磁率 11 , 限界周波数 $0.95 \mathrm{GHz}$ に比べ 軟磁気特性が向上した。

(3) X=1における初透磁率上昇の要因を検討した結果，磁化 值, 粒径, 密度および配向性の寄与は小さく, Mnイオン による磁気異方性および磁気歪みの効果によると判断し た.

以上のように $\mathrm{Fe}^{3+}$ イオンを $\mathrm{Mn}^{3+}$ イオンで置換した結果， $\mathrm{Z}$ 相単相が得られ，その置換量により磁気異方性が異なるので，
Mnイオンを含む超高周波用磁性材料を開発することが可能に なると考えられる。

\section{文献}

1) J.L.Snoek: Physica, 14(1948)207-217.

2) J.Smit and H.P.J.Wjin: Ferritte, Philips Technical Library, Eindhoven, The Netherlands, (1959)259, 278.

3) M.Sugimoto: Ferromagnetic Materials, Vol.3, Edited by E.P.Wolfarth, N. H. P. C, (1982)393.

4) E.Ogawa and O.Kubo: "Magnetic Properties Of $\mathrm{Co}-\mathrm{Zn}-\mathrm{Nb}$ Subsutituted Ba Ferrite Particles", Journal of The Magnetic Society of Japan, Vol.15, Supplement, No.S2, (1991).

5) O.Kubo and E.Ogawa: "Temperature Dependence of Magnetocrystalline Anisotropy for Sn Substituted Ba Ferrite Particles", IEEE Transactions on Magnetics, Vol.27, No.6, November, (1991).

6) A.Collomb, X.Obradors, A.Isalgue, M.Pernet and J.C.Joubert: "Cationic Distribution, Magnetic Properties, and Magnetic Structures of $\mathrm{BaFe}_{12-\mathrm{p}} \mathrm{Mn}_{\mathrm{p}} \mathrm{O}_{19}$ Hexagonal Ferrites", Proc. 4th. of Int. Conf. Ferrite, (1985)259-264.

7) X.Obradors, A.Collomb, M.Pernet, J.C.Joubert and A.Isalgue: "Structural and Magnetic properties of $\mathrm{BaFe}_{12-\mathrm{p}} \mathrm{Mn}_{\mathrm{p}} \mathrm{O}_{19}$ Hexagonal Ferrites", J. Magn. Magn. Mater., 44(1984)118.

8) 池田亮, 杮崎浩一, 平塚信之: " $\mathrm{Fe}^{3+}$ 置換による超高周波用 $\mathrm{CO}_{2} \mathrm{Z}$ 六方晶フェライトの研究 ", 粉体および粉末冶金 , 46 (1999)610-614.

9）太田恵造 : 磁気工学の基礎 II, 共立全畫, (1973)186.

10) 太田恵造 : 磁気工学の基礎 II, 共立全書, (1973)405-406. 